\title{
A Sexualidade Na Velhice: Representações Sociais De Idosos Frequentadores de Um Grupo de Convivência
}

\author{
Kay Francis Leal Vieira \\ Centro Universitário de João Pessoa, PB, Brasil.
}

\author{
Maria da Penha de Lima Coutinho \\ Universidade Federal da Paraíba, PB, Brasil.
}

Evelyn Rúbia de Albuquerque Saraiva

Universidade Federal da Paraíba, PB, Brasil.

\begin{abstract}
Resumo: Objetivou-se apreender as representações sociais dos idosos acerca da sexualidade. Trata-se de uma pesquisa descritiva com abordagem qualitativa, fundamentada nos aportes teóricos e metodológicos da Teoria das Representações Sociais. Participaram 30 idosos frequentadores de um grupo de convivência localizado em João Pessoa-PB. Foram utilizadas entrevistas em profundidade, cujo conteúdo foi submetido à análise de conteúdo temático. Os conteúdos representacionais abordaram os elementos constituintes da sexualidade, as mudanças decorrentes do envelhecimento, a importância das vivências sexuais para a pessoa idosa, bem como a percepção negativa dessas práticas por parte da sociedade em geral. Observou-se que as representações sociais da sexualidade apresentaram-se de forma semelhante à descrição científica, demonstrando similaridades entre o senso comum e o conhecimento erudito. Acredita-se que este estudo possa contribuir de forma parcimoniosa para a promoção de mudanças de atitudes acerca da sexualidade da pessoa idosa, trazendo benefícios para a qualidade de vida dessa população.

Palavras-chave: Sexualidade, Envelhecimento, Representações Sociais.
\end{abstract}

\section{Sexuality in Old Age: Social Representations of Elderly Patrons of a Social Group}

\begin{abstract}
This study aimed to identify the social representations of older people surrounding sexuality. This is a descriptive study with a qualitative approach, based on the theoretical and methodological contributions of the theory of social representations. Thirty elderly patrons of a support group located in João Pessoa, Brazil, participated. In-depth interviews were conducted, with the purpose of determining content subject to thematic content analysis. Representational content included the elements of sexuality, changes resulting from aging, importance of sexual experiences for the elderly, and negative perception of these practices on the part of society in general. It was observed that the social representations of sexuality were presented in a similar manner to scientific description, demonstrating similarities between common sense and scholarly knowledge. It is believed that this study will contribute sparingly to promote changes in attitudes about sexuality in the elderly, thereby bringing benefits to the quality of life of this population.
\end{abstract}

Keywords: Sexuality, Aging, Social Representations. 


\title{
Sexualidad en la Vejez: Representaciones Sociales de los Frecuentadores de un Grupo de Convivencia
}

\begin{abstract}
Resumen: Este estudio tuvo como objetivo identificar las representaciones sociales de las personas de la tercera edad sobre la sexualidad. Se trata de un estudio descriptivo con abordaje cualitativo, basado en los aportes teóricos y metodológicos de la Teoría de las Representaciones Sociales. Participaron 30 ancianos de un grupo de convivencia localizado en João Pessoa - Paranaiba. Se utilizaron entrevistas a profundidad, cuyo contenido fue sometido a análisis de contenido temático. Los contenidos representacionales abordaron los elementos propios de la sexualidad, los cambios derivados del envejecimiento, la importancia de las experiencias sexuales en las personas ancianas, así como la percepción negativa de estas prácticas por parte de la sociedad en general. Se observó que las representaciones sociales de la sexualidad se presentaron de una manera similar a la descripción científica, lo que demuestra las similitudes entre el sentido común y el conocimiento académico. Se cree que este estudio contribuirá de forma moderada para promover cambios en las actitudes sobre la sexualidad en las personas de la tercera edad, aportando beneficios a la calidad de vida de esta población. Palabras clave: Sexualidad, Envejecimiento, Representaciones Sociales.
\end{abstract}

\section{Introdução}

O processo de envelhecimento humano vem despertando, ao longo dos anos, o interesse de pesquisadores das mais diversas áreas do conhecimento científico, dentre elas, a ciência psicológica. A Psicogerontologia enfatiza os fatores subjetivos dessa etapa da vida, tendo como um de seus desafios a conciliação dos conceitos de desenvolvimento e envelhecimento, tradicionalmente vistos como antagônicos. Entretanto, na atualidade, esses processos já são vistos como coexistentes ao longo do ciclo vital, embora com pesos diferentes na determinação das mudanças evolutivas que, comumente, são chamadas de ganhos ou perdas (Neri, 2008).

$\mathrm{O}$ envelhecimento é um processo sequencial, individual, cumulativo, irreversível, universal, não patológico, de deterioração de um organismo maduro, próprio a todos os membros de uma espécie (Brasil, 2006). Trata-se de um processo de mudanças universais, pautado geneticamente para a espécie e para cada indivíduo, que se traduz em diminuição da plasticidade, em aumento da vulnerabilidade, em acúmulo de perdas evolutivas e no aumento da probabilidade de morte. Refere-se ao ato ou efeito de envelhecer, que significa ficar velho; parecer velho; durar muito tempo, permanecer, tornar-se desusado ou inútil (Neri, 2008; Silva, 2006).

Velhice é definida como a última fase do ciclo vital, delimitada por eventos de natureza múltipla, que incluem perdas psicomotoras, afastamento social, restri- ção em papéis sociais e especialização cognitiva. Em seu sentido etimológico, velhice refere-se à idade avançada, ao estado ou condição de ser velho (Neri, 2008). Para Mucida (2006), a velhice é um destino singular, onde cada um envelhece a seu próprio modo, pois cada um inscreverá algo que lhe é próprio, ou seja, o inscrito será reinscrito e reatualizado a partir dos traços de cada um.

O envelhecimento ocorre de maneira singular e complexa e não representa sinônimo de incapacidade funcional, dependência ou ausência de vivências sociais e sexuais. Mesmo na presença de perdas é possível vivenciar uma velhice bem-sucedida. Cachioni e Falcão (2009) ressaltam que a velhice bem-sucedida é associada à boa saúde física e mental, atividade e envolvimento com a vida. Reconhece-se, portanto, que ao tempo cronológico necessita-se acrescentar vida ativa, necessidade identificada como produto de esforços agenciados nos últimos anos, em grande medida, relacionados ao incremento da produção em ciência, tecnologia e práticas de atenção à saúde dos idosos (Lima, Silva \& Galhardoni, 2008).

Nessa perspectiva, são também reconhecidos os efeitos potencializadores das vivências sexuais, uma vez que a sexualidade pode ser compreendida como uma atividade que contribui positivamente para a qualidade de vida da pessoa idosa. Trata-se de um processo natural que obedece a uma necessidade fisiológica e emocional do indivíduo e que se manifesta de forma diferenciada nas diferentes fases do desen- 
volvimento humano. Visa o prazer, o bem-estar, a autoestima e a busca de uma relação íntima, compartilhando o amor e o desejo com outra pessoa para criar laços de união mais intensos (Soutto Mayor, Antunes \& Almeida, 2009). Corresponde a uma função vital do ser humano, na qual intervêm múltiplos fatores biológicos, psicológicos, sociais e culturais transmitidos de geração em geração, dando sentido e significado à existência humana (Fernandez \& Paniagua, 2007).

Freud (1905/1996), um dos pioneiros nos estudos da sexualidade humana, afirma em sua obra, Três ensaios sobre a teoria da sexualidade, que ela ocorre nos indivíduos desde o seu nascimento e que a prática sexual entre adultos pode ser bem mais livre do que supunham os teóricos moralistas do começo do século. Para ele, o período de desenvolvimento da sexualidade é longo e complexo até chegar à sexualidade adulta, na qual as funções de reprodução e de obtenção do prazer podem estar associadas, tanto no homem quanto na mulher. Essa afirmação contrariava as ideias predominantes de que o sexo estava associado, exclusivamente, à reprodução.

A concepção pioneira de Freud, ao afirmar que o prazer é um objetivo da sexualidade humana, desvinculava as vivências sexuais do significado exclusivo da reprodução. Sua tese foi confirmada com a recente emergência do conceito de saúde sexual e com a dissociação progressiva do conceito de reprodução, o que coloca em evidência a autonomização da vida sexual e sua importância para a realização e o bem-estar dos indivíduos durante toda a vida (Sousa, 2008).

Outros avanços no estudo das vivências sexuais foram realizados por Masters e Johnson (1988), cujas pesquisas são consideradas um marco no estudo da sexualidade. Esses autores foram pioneiros no estudo da fisiologia da resposta sexual e acreditavam que, para entender a complexidade da sexualidade humana, era preciso conhecer a anatomia e a fisiologia sexual e ter dados psicológicos e sociológicos. Segundo os referidos autores, existem mitos culturais acerca dessa temática, nos grupos constituídos por crianças, idosos e portadores de alguma patologia, os quais são vistos como seres assexuados.

Socialmente, tem-se considerado a pessoa idosa como assexuada, desprovida de desejos e de vida sexual, como se os anos the trouxessem uma inapetência neste aspecto vital do desenvolvimento humano (Gonzalez \& Brenes, 2007). Entretanto, a literatura atual tem demonstrado não existirem razões fisiológicas que impeçam as pessoas idosas, em condições satisfatórias de saúde, de apresentarem uma vida sexual ativa.

De acordo com Pascual (2002), existe, em nossa sociedade, um conceito de velhice deteriorado e negativo, especialmente no âmbito sexual. Não há apoio por parte dos profissionais de saúde, ao mesmo tempo em que os familiares põem obstáculos para impedir que seus idosos continuem sendo sexualmente ativos. Além disso, os meios de comunicação proporcionam uma visão pouco atrativa do processo de envelhecimento e, consequentemente, da pessoa idosa.

Tal fato é extremamente prejudicial aos idosos, haja vista que a sexualidade é um componente fundamental da qualidade de vida, essencial para manter as relações interpessoais saudáveis, o autoconceito e um senso de integridade. Está ligada ao senso de autoestima e, se negada, pode ter efeitos deletérios não só sobre a sexualidade em si, mas também em uma autoimagem, relações sociais e saúde mental (Bauer, McAuliffe e Nay, 2007).

$\mathrm{O}$ processo de envelhecimento não conduz a uma fase assexuada, mas tão somente a outra etapa no processo da sexualidade humana, a qual deve ser merecidamente vivenciada e apreciada (Fávero \& Barbosa, 2011). As vivências sexuais, independentemente da idade, proporcionam ao casal a possibilidade de se realizar pessoalmente, refletem a intimidade e a cumplicidade e enriquecem as relações humanas. Para os idosos, a sexualidade é fisiologicamente possível, emocional e afetivamente enriquecedora, porquanto fortalece a importância do carinho, do apego, a comunicação, o companheirismo e o cuidado mútuo (Urquiza, Thumala, Cathalifaud, Ojeda \& Vogel, 2008).

O tempo não dessexualiza a pessoa idosa, uma vez que a sexualidade está presente em todas as fases da vida, percorre "um caminho de faz e refaz, um caminho instável, em constante processo de transformação, assim como as pessoas, pois é parte indissociável delas" (Pires, 2006, p.2). No envelhecimento, a sexualidade varia tanto quanto os demais comportamentos, mas isso não implica necessariamente uma redução drástica da resposta sexual, já que ela depende fundamentalmente da atitude que cada pessoa adota diante da vida. Ocorre de maneira extremamente individual e não se processa do mesmo modo em todas as épocas, nem sequer da mesma forma em todos os indivíduos (Pascual, 2002).

A crença de que o envelhecimento e a ausência das vivências sexuais estejam inexoravelmente liga- 


\section{Vieira, Kay Francis leal; Coutinho, Maria Da Penha De lima; Saraiva, Evelyn Rúbia De Albuquerque}

(2015). A SEXUALIDAdE NA VELHICE.

dos é errônea e, de certa forma, contribui para o desconhecimento e preconceito acerca da sexualidade da pessoa idosa, o que consequentemente ocasiona prejuízos na qualidade de vida dessa população. (Vieira, 2012). Devido ao desconhecimento e à pressão cultural, muitos idosos que ainda possuem desejo sexual, experimentam, algumas vezes, sentimentos de culpa e de vergonha, pelo simples fato de se perceberem com vontade de procurar a obtenção do prazer. Estes padrões de comportamento criados pela sociedade limitam a sexualidade humana ao período da juventude, não sendo, portanto, reforçado pela sociedade na velhice. Ao contrário, o idoso é, muitas vezes, vítima de preconceito, o que acarreta grande perda em sua qualidade de vida.

No campo assistencial, a temática da sexualidade do idoso foi negligenciada pela área da saúde e pelo poder público, sendo a vida sexual da pessoa idosa tratada como algo inexistente. Consequentemente, a possibilidade de uma pessoa com mais de 60 anos ser infectada pelo vírus HIV era considerada remota. Entretanto, dados nacionais referem que o índice de HIV entre idosos já supera o de adolescentes entre 15 e 19 anos (Santos \& Assis, 2011). As explicações para esse aumento do número de casos de HIV em idosos referem-se ao envelhecimento populacional, ao aumento da sobrevida das pessoas com HIV/Aids, bem como ao acesso aos medicamentos para disfunções eréteis, em associação com a desmistificação do sexo na velhice (Silva \& Saldanha, 2012).

Em relação à sexualidade, ainda nos dias atuais, verificam-se dois problemas na abordagem dessa temática no momento do atendimento aos idosos. Por um lado, muitas vezes, o profissional de saúde sente-se envergonhado em fazer perguntas de âmbito sexual para os idosos, considerando falta de respeito tal indagação; e por outro, é comum o idoso ficar envergonhado e não ter coragem de fazer perguntas ao profissional, porque teme ser mal interpretado (Vieira, 2012).

De acordo com Viana e Madruga (2010), o idoso deve se sentir confortável para expressar emoções e necessidades, sem ficar temeroso ou envergonhado ao discutir problemas a respeito da sexualidade. Por outro lado, os profissionais de saúde devem ser isentos de preconceitos, falar diretamente sobre o assunto, responder a todas as questões, sem rodeios ou constrangimentos, mostrar que querem e precisam discutir o tema, com interesse, e mostrar dados científicos sobre alguns assuntos, caso o idoso deseje. As referidas autoras ressaltam, ainda, a necessidade de um ambiente com privacidade, o desenvolvimento de grupos de suporte e discussão com informações precisas para os que desejarem discutir velhos tabus e dar sugestões para possíveis resoluções de problemas.

As dificuldades de comunicação entre idosos e profissionais de saúde são notórias e, em parte, devem-se a falhas na formação acadêmica destes profissionais acerca da geriatria e gerontologia. Entretanto, Coelho (2006) ressalta que, ultimamente, os profissionais estão trabalhando para quebrar ou reduzir os preconceitos, os mitos, os tabus e os estereótipos que são atribuídos a ela. No entanto, ressalta-se que é de fundamental importância o cuidado, no sentido de não promover os contramitos, que são imagens superotimistas dos idosos, ao mesmo tempo não realistas. Percebe-se, então, que a informação deve ser passada de maneira correta, sincera e de fácil compreensão.

Apesar de o envelhecimento ser alvo de pesquisas nas mais diversas áreas do conhecimento científico, no tocante à temática da sexualidade verifica-se uma escassez de estudos. Em sua maioria, os estudos existentes abordam questões sobre disfunções e mudanças no funcionamento sexual do homem e da mulher, trazendo poucas reflexões acerca da forma como os idosos têm lidado emocionalmente com sua sexualidade. Para Gabriel, Neves e Dias (2010), fazem-se necessários estudos que elucidem a sexualidade dos idosos na perspectiva de sua qualidade de vida, uma vez que os mesmos nem sempre são compreendidos neste contexto.

No campo da Psicologia Social, especificamente, tem-se observado, nos últimos anos, o crescimento de estudos que contemplam a velhice. Deste modo, contribui, juntamente com a Psicologia da Personalidade, para o entendimento dos diversos fatores intrínsecos ao envelhecimento, o que promove intervenções psicossociais que propiciem melhores condições de vida a pessoa idosa (Neri, 2002).

No presente estudo, aborda-se a temática da sexualidade na velhice sob a ótica da Psicologia Social, utilizando-se para tanto a Teoria das Representações Sociais (Moscovici, 1978). Parte-se do pressuposto de que as representações sociais referem-se a uma forma de conhecimento, socialmente elaborada e partilhada, com um objetivo prático, e que contribui para a construção de uma realidade comum a um conjunto social (Jodelet, 2001). 
Trata-se de um saber prático, produzido nas interações e na comunicação entre os grupos sociais, os quais refletem a situação dos indivíduos no que se refere aos assuntos cotidianos (Ferreto, 2010). São consideradas necessárias, pois guiam o indivíduo no modo de nomear e definir conjuntamente os diferentes aspectos da realidade diária, no modo de interpretar esses aspectos, tomar decisões e, eventualmente, posicionar-se frente a eles de forma defensiva (Jodelet, 2001).

A representação social é o meio pelo qual os seres humanos representam objetos de seu mundo. Ferramenta de pensamento, é também uma placa giratória entre o indivíduo e o grupo, entre o material e o ideal (Lahlou, 2011). Para Trindade, Santos e Almeida (2011), as representações sociais têm, em seu bojo, a ideia de um conhecimento construído por um sujeito ativo, em íntima interação com o objeto culturalmente construído, que revela as marcas tanto do sujeito quanto do objeto, ambos inscritos social e historicamente.

Segundo Vala e Monteiro (2004), as representações sociais apresentam uma dimensão funcional e prática, que acaba por ser evidente na organização dos comportamentos, das atividades comunicativas, na argumentação e na explicação cotidianas e na diferenciação dos grupos sociais. A elaboração e o funcionamento de uma representação podem ser compreendidos por meio dos processos de objetivação e ancoragem. Jodelet (2001) afirma que a objetivação é o processo pelo qual o indivíduo reabsorve um excesso de significações, materializando-as; ou seja, é a construção formal de um conhecimento pelo indivíduo. Já a ancoragem, como instrumento do saber, é uma modalidade que permite compreender como os elementos de representação não só exprimem relações sociais, mas também contribuem para construí-las. Portanto, ela assegura o elo entre a função cognitiva de base da representação e a social, bem como fornece à objetivação os elementos imaginativos para servir na elaboração de novas representações.

Desse modo, identificar as representações sociais acerca da sexualidade é compreender as formas que as pessoas utilizam para criar, transformar e interpretar esse construto vinculado à sua realidade. Compreende-se, portanto, que apreender as representações sociais dos idosos acerca da sexualidade na velhice significa compreender uma interpretação da realidade vivida e falada por esse grupo social, que direciona comportamentos e comunicações.
Frente ao exposto, o presente estudo objetivou investigar as representações sociais da sexualidade elaboradas por idosos frequentadores de um grupo de convivência localizado no município de João Pessoa, Paraíba.

\section{Método}

Tratou-se de uma pesquisa descritiva, com abordagem qualitativa, que utilizou uma amostra do tipo não probabilística de conveniência, composta por 30 idosos, frequentadores de um grupo de convivência do município de João Pessoa (PB). O referido grupo é vinculado ao Instituto de Previdência do Município (IPM) e, no local, são oferecidas, gratuitamente, atividades como hidroginástica, alongamento, dança, natação, informática, oficina de memória e coral.

Foi utilizada a técnica de entrevista em profundidade, também denominada de entrevista aberta, entendida como aquela em que o entrevistado tem a possibilidade de discorrer sobre o tema proposto, sem respostas ou condições prefixadas pelo pesquisador (Minayo, 2007). Durante a entrevista, os participantes foram convidados a falar de forma livre e aberta sobre o significado da sexualidade. O número de entrevistas foi estabelecido segundo o critério de saturação definido por Sá (1998). Os participantes responderam ainda um questionário biossociodemográfico objetivando-se a obtenção do perfil da amostra.

O projeto foi submetido à avaliação do Comitê de Ética em Pesquisa do Centro Universitário de João Pessoa - UNIPÊ e, mediante parecer favorável, foi realizada a coleta dos dados. Inicialmente foi realizado um contato com a coordenadora do grupo de convivência, para a qual foi apresentado o projeto e solicitado autorização para realização da pesquisa.

Os participantes foram previamente informados a respeito dos objetivos e procedimentos da pesquisa, bem como, da confiabilidade dos dados e do anonimato da sua colaboração. Também foi destacado o caráter voluntário da pesquisa, deixando-os à vontade para escolher participar ou não. Em seguida, foi solicitado que lessem e assinassem o Termo de Consentimento Livre e Esclarecido, de acordo com as normas da Resolução no 466/12 sobre Pesquisa Envolvendo Seres Humanos (Brasil, 2012)

As entrevistas foram realizadas de forma individual, sendo seu conteúdo submetido à técnica de Análise de Conteúdo Temático (Bardin, 2010), que se refere a um conjunto de técnicas de análise das co- 


\section{Vieira, Kay Francis leal; Coutinho, Maria Da Penha De lima; Saraiva, Evelyn Rúbia De Albuquerque}

(2015). A SEXUALIDAdE NA VELHICE.

municações visando obter indicadores que permitam a inferência de conhecimentos relativos às condições de produção/recepção das mensagens.

\section{Resultados}

Participaram da pesquisa 30 idosos, sendo a maioria do sexo feminino (80\%). Em relação à idade, observou que $33,3 \%$ dos idosos encontravam-se na faixa etária de $60-64$ anos; $46,7 \%$ na faixa etária de 65-69 anos, e 20\% dos idosos apresentaram idades iguais ou superiores a 70 anos. No que concerne aos aspectos econômicos, constatou-se que $6,7 \%$ dos participantes possuíam renda familiar de 1 a 3 salários mínimos; $73,3 \%$ possuía renda de 4 a 6 salários mínimos e $20 \%$ renda familiar igual ou superior a 7 salários mínimos. No que se refere à religião, $76,6 \%$ dos participantes se definiram como católicos; $16,7 \%$ evangélicos e $6,7 \%$ adeptos da doutrina espírita.

Conforme a tabela a seguir, a análise das representações sociais da sexualidade na velhice foi composta por 277 unidades temáticas, distribuídas em 4 categorias e 17 subcategorias, advindas das interlocuções dos idosos.
A primeira subcategoria referente à categoria Elementos constituintes, denominada Prazer, correspondeu a $12,1 \%$ dos recortes analisados e descreve a sexualidade como uma atividade prazerosa, podendo ser exemplificada através dos discursos a seguir:

“[...] sexualidade é prazer, é a satisfação do prazer, sexualidade é a busca do prazer, é uma coisa muito prazerosa, é o prazer que sentimos em estar com alguém, eu ainda sinto prazer, o idoso pode sentir prazer, acho importante que o idoso ainda possa sentir prazer, temos que aproveitar esses prazeres da vida."

A maior incidência de respostas referentes aos elementos constituintes da sexualidade foi observada na subcategoria Relação Sexual, correspondente a 16,1\% das unidades temáticas dessa categoria. Nesse contexto, a sexualidade foi representada através do ato sexual:

“[...] sexualidade é fazer sexo... é a atividade sexual...é sexo... o sexo faz parte... não é só sexo... não é apenas o ato sexual em si... o idoso ainda tem interesse por sexo... nós precisamos de sexo [...] nós ainda fazemos sexo [...] eu entendo que é o sexo..."

Tabela 1

Análise de Conteúdo das Representações Sociais da Sexualidade na Velhice.

\begin{tabular}{lll}
\hline Classe temática $(f)$ & Categoria $(f)$ & Subcategorias $(f)$ \\
\hline Sexualidade na & Elementos constituintes & 1.1 Prazer (21) \\
Velhice & $(174)$ & 1.2 Relação sexual (28) \\
& 1.3 Carinho (23) \\
& 1.4 Intimidade (13) & 1.5 Companheirismo (12) \\
& 1.6 Desejo (16) \\
& 1.7 Amor (22) \\
& 1.8 Vida (21) \\
& 1.9 Autoestima (12) \\
& 1.10 Atitudes (06) \\
\cline { 2 - 3 } & 2.1 Positivas (23) \\
& Mudanças advindas do & 2.2 Negativas (12) \\
envelhecimento & 2.3 Inexistentes (07) \\
& $(42)$ & 3.1 Necessária (22) \\
\cline { 2 - 3 } & Importância das vivências sexuais & 3.2 Desnecessária (06) \\
& $(28)$ & 4.1 Aceitação (11) \\
\cline { 2 - 3 } & Percepção da sociedade & 4.2 Rejeição (22) \\
& $(33)$ &
\end{tabular}

${ }^{*} f=$ frequência das evocações. 
Na subcategoria Carinho, composta por $13,2 \%$ dos recortes analisados, encontram-se as unidades temáticas referentes à descrição da sexualidade objetivadas no ato de carinho mútuo entre o casal, conforme os exemplos:

“[...] sexualidade significa carinho...é o acariciar...é a troca de carícias... é fazer carinho um no outro... são as carícias... todas aquelas preliminares... troca de carinho do casal... são as carícias iniciais."

Na subcategoria Intimidade (7,5\%) encontram-se as falas dos participantes que descreveram a sexualidade ancorando-a na relação íntima do casal:

"[...] é quando um casal tem sua intimidade...é muito mais a intimidade do que o sexo... é relacionar-se intimamente com uma outra pessoa...é essa coisa de intimidade...não tenho a possibilidade de ter essa intimidade com meu marido... temos o direito de ter nossa intimidade..."

O Companheirismo também emergiu no discurso dos participantes, representando $6,9 \%$ das unidades temáticas. A sexualidade, para os participantes, representa algo que vai além do físico, envolvendo aspectos emocionais, sendo de extrema importância as relações de amizade e companheirismo entre o casal, conforme pode ser observado nos discursos a seguir:

“[...] sexualidade na velhice é muito mais aquele companheirismo... é ter um companheiro... é ser amigo... ter amizade entre o casal... uma boa conversa... dar e receber atenção... é companhia para todas as horas ... o idoso precisa ter alguém... é fundamental o companheirismo entre o homem e a mulher... nós queremos é companheirismo...".

Na sexta subcategoria foram agrupados os recortes referentes ao Desejo, correspondendo a $9,2 \%$ dos recortes analisados na categoria:

“[...] é o desejo... é a atração... é uma maneira de demonstrar que somos desejados... é muito bom saber que ainda despertamos desejo em alguém... a gente sente desejo... o velho também tem desejos... mesmo velhos ainda sentimos desejo um pelo outro... eu me sinto desejada..."
A sétima subcategoria refere-se à representação social da sexualidade mediante o sentimento de Amor $(12,6 \%)$ existente entre o casal idoso. As falas dos participantes ressaltam a importâncias das vivências amorosas para a pessoa idosa, conforme pode ser observado nas falas a seguir:

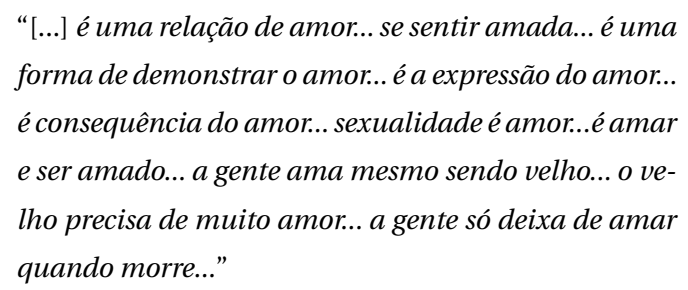

Na oitava subcategoria, denominada Vida e composta por $12,1 \%$ dos recortes analisados, encontram-se as representações da sexualidade ancoradas no viver e aproveitar a vida, conforme é possível perceber nos recortes abaixo:

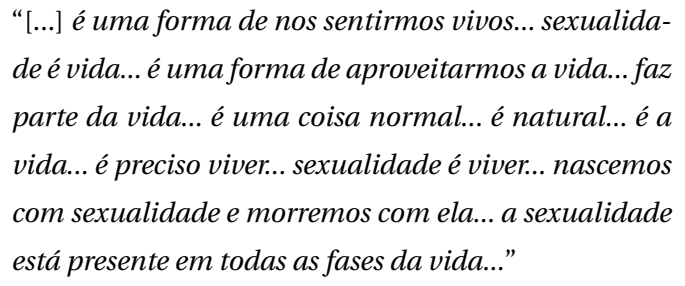

A categoria Autoestima correspondeu a $6,9 \%$ das unidades temáticas analisadas e ressalta a importância da aceitação do envelhecimento e de suas consequências, fortalecendo assim a autoestima do idoso. Os recortes a seguir, exemplificam tal fato:

\footnotetext{
“[...] sexualidade tem a ver com a autoestima... se você não se sente bem não se aceita, não vai desfrutar da sexualidade... faz a gente se sentir bonita e atraente... melhora a nossa autoestima... faz bem pro nosso ego... faz bem pra nossa autoestima... sexualidade é a autoestima...”
}

Por fim, a última subcategoria referente aos Elementos biopsicossociais da sexualidade do idoso diz respeito às Atitudes e representa 3,4\% dos recortes analisados:

\footnotetext{
“[...] é um conjunto de atitudes e sentimentos... depende das nossas atitudes diante da vida... é uma questão de atitude... é preciso ter atitude... a sexualidade é muito mais uma atitude..."
} 


\section{Vieira, Kay francis leal; Coutinho, Maria Da Penha De lima; Saraiva, Evelyn Rúbia De Albuquerque (2015). A sexualidade na Velhice.}

A Categoria 2 foi denominada Mudanças advindas do envelhecimento, uma vez que refere-se às alterações no campo das vivências sexuais decorrentes da chegada da velhice. Foi formada por três subcategorias, que classificam as referidas mudanças em Positivas (54,8\%), Negativas (28,6\%) e Inexistentes (16,6\%). Em relação às mudanças apontadas como Positivas, os atores sociais destacaram:

\footnotetext{
“[...] aproveitamos mais hoje do que quando éramos jovens...existe muito mais carinho e cumplicidade... o sentimento de acolhimento cresce... a intimidade aumenta e a vergonha e a insegurança diminuem... tem mais amor... tem mais companheirismo... é uma coisa mais sincera... é menos superficial...para os jovens está mais na aparência, na aventura e na falta de vínculo...quando a gente envelhece passa a ter outras prioridades..."
}

Quanto às mudanças de ordem Negativas, foram destacadas as seguintes falas:

\footnotetext{
“[...] a disposição e o ritmo não são mais os mesmos... não existe mais aquele desejo todo... o desejo e a frequência diminuem... a atividade sexual diminui... o preparo físico já não é o mesmo... problemas de saúde podem interferir... com a chegada da velhice chega também o cansaço... tem as doenças e aí a sexualidade fica limitada..."
}

Complementando a categoria Mudanças na sexualidade, a terceira subcategoria foi denominada Inexistente, uma vez que retrata recortes das falas dos participantes que informaram não sentirem nenhuma diferença entre a sexualidade na velhice e no período anterior a ela. Esta subcategoria é responsável por $16,6 \%$ das unidades temáticas e seu conteúdo representacional é descrito a seguir:

\footnotetext{
“[...] meu interesse por sexo é o mesmo... sempre tenho disposição... não notei nenhuma diferença... tenho disposição e estímulo... nunca perdi o interesse... se você tem motivação sempre terá sexualidade..."
}

Em relação à terceira categoria denominada $\mathrm{Im}$ portância das vivências sexuais, houve o surgimento de duas subcategorias. Na primeira delas encontram-se as falas dos participantes que afirmam ser a prática da sexualidade Necessária $(78,6 \%)$ para a vida do idoso:

\begin{abstract}
“[...] é muito importante para o idoso... não temos como viver sem ela... é fundamental para as nossas vidas... nos faz sentir mais dispostos e felizes...ponto crucial no bem-estar do idoso... tão importante para o idoso quanto para o jovem... o velho precisa disso, precisa da sexualidade..."
\end{abstract}

Já na segunda subcategoria referente à Importância da sexualidade para a vida do idoso, encontram-se aqueles discursos que afirmam ser Desnecessária $(12,4 \%)$ esta prática na velhice, conforme podemos observar nos recortes a seguir:

“[...] não acho que o idoso precise disso... não gosto, nunca gostei... acho que sempre fui frígida... fazia só porque ele queria mesmo... nunca senti falta dessas coisas... nunca gostei dessas coisas..."

Por fim, tem-se a Categoria 4, denominada Percepção da sociedade, que retrata as representações da sociedade em geral acerca da sexualidade do idoso sob a ótica dos participantes. Seu conteúdo representacional foi classificado em duas subcategorias. A primeira delas, Aceitação, corresponde a 33,3\% das unidades temáticas analisadas e pode ser exemplificada da seguinte forma:

\footnotetext{
"[...] a sociedade está mais preocupada com o bem-estar do idoso... sabem que os idosos podem sim ter sexualidade... já foi muito pior, mas está sendo mudado... já estão pensando diferente, estão aceitando mais isso... a sociedade hoje em dia trata melhor o velho... não acho que a sociedade discrimine ou exclua o velho da sexualidade... hoje o velho tem espaço, temos voz..."
}

Em relação à subcategoria Rejeição (66,7\%), os atores sociais enfatizaram em suas falas a questão do preconceito e da discriminação social percebida pelo idoso:

\footnotetext{
“[...] sexualidade na velhice é um tabu... ninguém acha que a gente ainda faz alguma coisa... acham que estamos velhos demais para pensar em sexo... a sociedade esquece que o idoso é gente... acham que a gente só serve pra dar trabalho e gasto... não acreditam que o idoso possa gostar dessas coisas... vão ser chamadas de velha assanhada e pervertida... a sociedade não vê com bons olhos..."
}

\section{Discussão}

O discurso dos idosos participantes ficou focalizado em quatro eixos temáticos: os elementos cons- 
titutivos da sexualidade, a sua importância e sua repercussão na vida do idoso, assim como a apreciação da sociedade acerca da sexualidade da pessoa idosa.

$\mathrm{Na}$ apreensão das representações sociais da sexualidade destacaram-se ancoragens em aspectos vitais, relação corpo/sexo, elementos psicoafetivos e sociais. Realçam algumas dicotomias e ambivalências próprias do ciclo vital, objetivadas na relação jovem versus idoso, corpo envelhecido versus interesse e motivação para o sexo. As ambivalências concentram-se na avaliação dos participantes quanto à importância das vivências sexuais nos idosos, alternando entre muito importante e sem importância. Quanto à percepção da sociedade acerca da sexualidade dos idosos, os participantes também construíram suas representações sociais em elementos ambivalentes: de um lado, ocorre a aceitação da sexualidade dos idosos e, de outro lado são identificados preconceitos e discriminação.

As representações sociais concentraram-se, majoritariamente, nos Elementos constituintes da sexualidade, sendo suas unidades temáticas agrupadas em dez subcategorias (prazer, relação sexual, carinho, intimidade, companheirismo, desejo, amor, vida, autoestima e atitudes), demonstrando assim, o caráter complexo e multifacetado da sexualidade. Esse caráter do fenômeno estudado corrobora com os estudos de Gabriel et al. (2010), bem como de Moura, Leite e Hildebrandt (2008) que identificaram que os idosos possuem clareza e entendimento sobre a temática, compreendendo-a em seu sentido amplo, significando bem mais que a simples relação sexual.

Embora compreendam que a sexualidade abrange diversos fatores, os participantes representaramna principalmente, através da relação sexual, subcategoria esta que foi responsável pela maior incidência de respostas referentes aos elementos constituintes da sexualidade. Observa-se, portanto, que os participantes entendem a sexualidade como sinônimo do ato sexual, corroborando o estudo de Frugoli e Maganhães-Junior (2011). As relações sexuais são uma realidade cotidiana para os idosos, envolvendo sentimentos e emoções, que, por sua vez, lhes proporcionam satisfação física e mental. Embora durante muito tempo a sexualidade tenha sido compreendida como algo exclusivamente ligado à reprodução, sabe-se que, atualmente, a relação sexual deixou de ser uma mera necessidade biológica de perpetuação da espécie, para se tornar, também, uma necessidade psicológica profundamente influenciada pelos padrões sociais e culturais (Silva, 2006).

Percebe-se uma valorização da privacidade do casal diante da necessidade de um espaço para que os idosos desfrutem de momentos íntimos livres de interrupções ou constrangimentos. Um dos obstáculos para esta aquisição refere-se ao fato do idoso morar com filhos. Conforme ressalta Ribeiro (2002), em família, os filhos são os primeiros a negar a sexualidade dos pais, interpretando a necessidade sexual destes como algo depreciativo, como sinal de segunda infância ou demência.

Observa-se nesse contexto, que os idosos continuam tendo desejos semelhantes aos que tinham quando jovens, embora agora possam apresentar maiores limitações em razão das alterações fisiológicas que, às vezes, dificultam um relacionamento mais íntimo. Entretanto, sabe-se que os idosos descobrem outros prazeres, adaptam-se a sua condição e conseguem encontrar para cada problema um novo modo de viver (Moura et al., 2008). Neste sentido, os resultados demonstram que os idosos devem ser vistos como indivíduos que possuem desejo, necessidades sexuais e que fazem projetos para o futuro, corroborando o estudo de Maschio, Balbino, De Souza e Kalinke (2011).

Mediante os discursos, observou-se uma naturalização da sexualidade, percebida como algo presente e necessário para a vida do indivíduo, independentemente da fase do desenvolvimento. Os idosos representaram a sexualidade como algo inerente à vida do ser humano, que está presente em nossas vidas desde o nascimento até a morte, ressaltando ser possível ter uma vida sexual ativa e saudável na velhice.

Ressalta a importância da aceitação do envelhecimento e de suas consequências, fortalecendo assim a autoestima do idoso. De acordo com Urquiza et al. (2008), ocorre com frequência a autopercepção negativa do corpo por parte dos idosos, onde a pessoa idosa deixa de ver a si mesma como atraente, acreditando que seu corpo está fora dos padrões de beleza estipulados pela sociedade.

De acordo com Martins (2012), em nossa sociedade, caracterizada como urbana e capitalista, observa-se uma supervalorização da juventude, traduzida numa preocupação excessiva com a aparência e o culto ao corpo esbelto, saudável e jovial. Tenta-se, através de diversos meios, adiar o envelhecimento, por se temerem a finitude e as repercussões sociais.

Nesse mesmo direcionamento, Silva, Marques e Fonseca (2009) ressaltam que a sociedade ocidental mo- 


\section{Vieira, Kay Francis leal; Coutinho, Maria Da Penha De lima; Saraiva, Evelyn Rúbia De Albuquerque}

(2015). A SEXUALIDAdE NA VELHICE.

derna está baseada no capital, na produção e no consumo, para a qual a juventude é um valor central. Consequentemente, o lugar social destinado ao velho tem valor negativo, onde o corpo dos idosos é quase invariavelmente associado à doença, invalidez, decrepitude e proximidade da morte. Envelhecer passa a ser o ficar cada vez mais distante do ideal da perfeição do corpo, já que a beleza e a juventude são associadas à saúde.

É fundamental ter um bom relacionamento consigo mesmo desde a juventude, pois a imagem que o idoso tem de si próprio se inspira naquilo que soube desenvolver e realizar no conjunto de suas experiências anteriores: familiares, profissionais, culturais, sociais, sentimentais e artísticas (Capodieci, 2000). Dessa forma, entende-se que um fator extremamente relevante para um bom aproveitamento das vivências sexuais consiste na autoestima do idoso, pois é necessário que, em primeiro lugar, ele se ame e se aceite como realmente é.

Outro importante eixo temático que emergiu do discurso dos participantes aborda as Mudanças advindas do envelhecimento, que variaram de positivas a negativas, e ainda foram registradas objetivações que assinalaram a inexistência de mudanças na sexualidade comparadas às fases da juventude, maturidade e velhice.

Estudos de Amaral et al. (2011) apontaram que na velhice há uma diminuição de práticas sexuais, devido às limitações em razão das alterações fisiológicas e, por vezes, patológicas, que dificultam um relacionamento mais íntimo, corroborando com os dados colhidos. Todavia, alguns idosos relataram que a fase do envelhecimento tem sido de grande descoberta na vida sexual e amorosa. Resultados semelhantes foram encontrados por Gradim, Sousa e Lobo (2007) que constataram que a sexualidade não se estagna com o envelhecimento e que, embora existam alguns idosos que não mais possuem vida sexual ativa, existem outras formas de se expressar a sexualidade como carícias e trocas de afeto comumente utilizadas pela população idosa.

O terceiro eixo temático identificado na fala dos idosos, Importância das vivências sexuais, revela que a sexualidade e a possibilidade de vivenciá-la de forma saudável e prazerosa são extremamente possíveis e positivas durante a velhice, de acordo, portanto, com os achados de Frugoli e Maganhães-Junior (2011). Não obstante este entendimento, em alguns casos, devido a algumas limitações físicas, os idosos entrevistados acreditam que seja necessária alguma adaptação para a vivência plena da vida sexual. Nesses casos, conforme ressalta Silva (2003), o ato sexual deixa de ser a principal fonte de prazer e o erotismo apresenta-se mais difuso, passando a manifestar-se por formas de estimulação e zonas erógenas diferenciadas. O importante é que o casal esteja disposto a desfrutar de alternativas para vivenciar de forma prazerosa sua sexualidade.

Cada idoso é único e singular, portanto vai vivenciar diferentemente sua sexualidade, assim como qualquer ser humano, em qualquer fase da vida. As vivências sexuais oferecem uma oportunidade de expressar sentimentos, fornecendo provas afirmativas de que se pode contar com o corpo e seu funcionamento, trazendo a emoção e a alegria de estar vivo (Pires, 2006)

As representações sociais apreendidas também revelam objetivações sobre a falta de necessidade do sexo para os idosos. Observa-se que tais respostas coadunam-se com o estudo de Frugoli e Maganhães-Junior (2011), onde se verificou, principalmente, nos discursos das mulheres idosas, reflexos de uma educação repressora recebida no passado, que fez com que elas não usufruíssem de sua sexualidade nesse momento da vida.

É necessário considerar que a maioria dos idosos recebeu, em sua criação proveniente de outra geração, informações diferenciadas acerca da sexualidade. Essas informações caracterizavam a sexualidade como algo exclusivamente relacionado à procriação. Aspectos religiosos também contribuíram para essa visão limitada da sexualidade, relacionando as vivências sexuais a algo pecaminoso (Vieira, 2012).

Especialmente em relação às mulheres, Corrales, Rodriguez, Miranda e Inclán (2010) afirmam que, muitas vezes, elas acreditam erroneamente que, com o término de sua função reprodutiva, encerram-se também as suas funções sexuais. Entretanto, os autores ressaltam que tal fato se deve apenas aos aspectos sociais e culturais e que não há causas fisiológicas para essa estagnação.

Por fim, o último eixo temático advindo da análise dos discursos dos idosos, foi denominado de Percepção da sociedade, que retrata as representações da sociedade em geral acerca da sexualidade do idoso sob a ótica dos participantes. A esse respeito, Pires (2006) ressalta que a maioria das pessoas tem uma imagem pré-formada a respeito da velhice, sendo um dos estereótipos mais conhecidos o da figura "assexuada, despojada de sensualidade e utilidade” (p. 2). Para Dantas, Silva e Loures (2002), existe uma dificul- 
dade de compreensão da atividade sexual como uma função fisiológica, que vai muito além do ato sexual em si. A sexualidade abrange outros aspectos da vida do indivíduo como o afeto, o carinho, o desejo, as fantasias, o companheirismo, sendo muito importante para a qualidade de vida da pessoa idosa.

Conforme ressaltam Santos e Carlos (2003), resgatar o direito a uma vida sexual na velhice implica poder pensar o amor em suas formas de transformação libidinal. Significa compreendê-lo em um sentido amplo, que passa pela ternura, pelos contatos físicos que erogenizam o corpo, como o olhar, o toque, a voz, redescobrindo as primeiras formas de amor do ser humano. Segundo Mucida (2006), o modo de expressar o desejo e a sexualidade modifica-se com o tempo, pois os investimentos e valores também mudam. Dessa forma, não é a velhice que determina a ausência do desejo ou a diminuição das relações sexuais, mas é a própria complexidade do desejo que impõe novas cores para tecer a sexualidade na velhice.

A sexualidade, vivida com paixão e intensidade durante a juventude, não tem porque não ser vivida da mesma maneira quando nos tornamos idosos, pois, como referem Vazquez, Cabrera e Avich (2008), ela é muito mais do que sexo, corresponde a uma função humana de dimensão psicossocial, que não regida, exclusivamente, por instinto. Embora se apresente de forma diferenciada em cada etapa da vida, a sexualidade tem comportamento vitalício e desenvolturas evolutivas que vão desde o nascimento até a morte, o que evidencia o desejo sexual, que permanece intacto, e a persistência da vontade de intimidade e afetividade, tão reprimida na velhice (Sousa, 2008).

Segundo Wallace (2003), a sexualidade vai além da relação sexual, ela se caracteriza como algo não apenas possível, mas necessário. Para alguns idosos, isso significa ter relações sexuais. Para outros, a sexualidade pode incluir conversa íntima e proximidade ou outros métodos de realização sexual a critério do casal.

\section{Conclusão}

O envelhecimento populacional representa um fenômeno mundial que vem demandando desafios constantes aos profissionais de diversas áreas do conhecimento científico. Os indicadores, sejam de ordem biológica, psicológica ou social, apontam para a necessidade de redefinição de conceitos e valores, no sentido de garantir um envelhecimento ativo e socialmente inserido.
Durante muito tempo, a velhice foi vista apenas como um período de declínio e perdas, contribuindo para a existência de estereótipos e preconceitos em relação a pessoa idosa. Compreender o processo de envelhecimento considerando apenas os seus aspectos negativos impossibilita a percepção de fatores importantes que são vivenciados apenas nessa etapa do desenvolvimento, como a experiência, objetivada por uma visão mais ampla e global da existência humana.

Os resultados dessa pesquisa apontaram que a sexualidade é um elemento essencial para uma boa qualidade de vida na velhice, sendo de fundamental importância a compreensão da forma como os idosos a percebem e vivenciam. Permitiram também a compreensão dos pensamentos, sentimentos e percepções dos idosos, bem como suas crenças, valores e atitudes.

Observou-se a elaboração de um campo semântico em torno da sexualidade constituído por uma multiplicidade de elementos, como o carinho, a cumplicidade, a intimidade, o ato sexual, dentre outros. Desta forma, infere-se que os idosos não compreendem a sexualidade como algo limitado, e sim como um processo complexo do qual fazem parte outras emoções e comportamentos que não se reduzem apenas às relações sexuais. Nesse sentido, os idosos extrapolaram o significado meramente fisiológico da sexualidade, compreendendo-a em seu sentido macro.

De maneira geral, os atores sociais demonstraram entendimento acerca da sexualidade, bem como aceitação das práticas sexuais na velhice, embora alguns tenham ressaltado a percepção negativa da sociedade quanto a essa realidade. Foram apontadas mudanças tanto positivas quanto negativas decorrentes do processo de envelhecimento, bem como destacada a importância dos idosos vivenciarem sua sexualidade de maneira saudável e prazerosa. As representações dos idosos acerca da sexualidade foram permeadas de conhecimentos oriundos do senso comum, interligados com experiências de vida dos mesmos.

A sexualidade do idoso é uma temática ainda carente de pesquisas, haja vista que a maioria dos estudos existentes se detém aos aspectos fisiológicos negativos, como as disfunções sexuais, por exemplo. Estudos capazes de apreender os aspectos subjetivos das vivências sexuais na velhice são de suma importância, pois possibilitam a compreensão dos sentimentos e emoções existentes na vida cotidiana dos idosos, que acabam por direcionar os comportamentos dessa população. 


\section{Vieira, Kay Francis Leal; Coutinho, Maria Da Penha De lima; Saraiva, Evelyn Rúbia De Albuquerque (2015). A SEXUALIDAdE NA VELHICE.}

Espera-se que este estudo possa promover reflexões e auxiliar nas mudanças de atitudes de familiares, cuidadores, profissionais da saúde, enfim, de toda a sociedade no que diz respeito à sexualidade dos idosos, desmistificando tabus e contribuindo para diminuição do preconceito. Acredita-se, também, que a compreensão da forma como os idosos veem e lidam com a

\section{Referências}

Amaral, R. K. S., Nascimentos, W. D. M., Vieira, J. D. R., Teles, M. A. B., Souza, C. M. S., Alves, M. C. S., \& Leite, M. G. (2011). Percepção dos idosos sobre sexualidade na terceira idade. In: Anais XII Seminário de Pesquisa e Pós- graduação (pp. 1-4). Universidade Estadual de Montes Claros.

Bardin, L. (2010). Análise de conteúdo. Lisboa: Edições 75. Bauer, M., McAuliffe, L., \& Nay, R. (2007). Sexuality, health care and the older person: an overview of the literature. International Journal of Older People Nursing, 2 (1), 63-68.

Brasil. (2006). Ministério da Saúde, Secretaria de Atenção à Saúde, Departamento de Atenção Básica. Envelhecimento e saúde da pessoa idosa (Cadernos de Atenção Básica - n.o 19, Série A: envelhecimento e saúde da pessoa idosa). Brasília, DF: Ministério da Saúde.

Brasil (2012). Ministério da Saúde, Conselho Nacional de Saúde. Resolução 466, de 12 de dezembro 2012. Diretrizes e normas regulamentadoras de pesquisas envolvendo seres humanos. Brasília, DF: Ministério da Saúde.

Cachioni, M., \& Falcão, D.V.S. (2009). Velhice e Educação: possibilidades e benefícios para a qualidade de vida. Em D.V.S. Falcão, \& L.F.Araújo (Eds.), Psicologia do envelhecimento: relações sociais, bem-estar subjetivo e atuação profissional em contextos diferenciados (pp. 175-194). Campinas: Alínea.

Capodieci, S. (2000). A idade dos sentimentos: amor e sexualidade após os sessenta anos. Bauru: EDUSC.

Coelho, A. V. R. (2006). O sentido subjetivo da sexualidade na terceira idade (Dissertação de mestrado). Universidade Católica de Goiás, Goiânia, Goiás.

Corrales, L. A. W., Rodriguez, Y. A., Miranda, M. C. D. \& Inclán, A. G. (2010). La sexualidad en la tercera edad. Factores fisiológicos y sociales. Revista Médica Eletrônica, 32(3),1-5.

Dantas, J. M. R., Silva, E. M., \& Loures, M. C. (2002). Lazer e sexualidade no envelhecimento humano. Estudos Goiânia, 29(5), 1395-1442. sexualidade, sob a ótica da Teoria das Representações Sociais, possibilita uma complementaridade entre o saber científico e o senso comum. Ressalta-se, por fim, que continuar exercendo as atividades sexuais na velhice é um desejo pessoal de cada um e, se desejado, é um exercício prazeroso e saudável, capaz de promover benefícios à qualidade de vida da pessoa idosa.

Fávero, M. F., \& Barbosa, S. C. S. (2011). Sexualidade na velhice: os conhecimentos e as atitudes dos profissionais de saúde. Terapia Sexual, 14(2), 11-39.

Fernandez, M. L., \& Paniagua, S. C. (2007). La sexualidad em la persona adulta mayor. In A. C. M. Gonzalez, \& M. R. Brenes (Eds.), Envejece la sexualida$d e$ ? (pp. 15-35). Buenos Aires: Espacio Editorial.

Ferreto, L. E. (2010). Representação social no envelhecimento humano. In W. Malagutti, \& A. M. A. Bergo (Eds.), Abordagem interdisciplinar do idoso (pp. 23-36). Rio de Janeiro, RJ: Rubio.

Freud, S. (1996). Três ensaios sobre a teoria da sexualidade (Vol. 2). Rio de Janeiro, RJ: Imago. (Trabalho original publicado em 1905).

Frugoli, A., \& Magalhães Junior, C. A. O. (2011). A sexualidade na terceira idade na percepção de um grupo de idosas e indicações para a educação sexual. Arquivos de Ciências da Saúde UNIPAR, Umuarama, 15(1), 85-93.

Gabriel, G.L.L., Neves, S., \& Dias, L.G. (2010). Sexualidade na vivência de idosos. Cuidado é fundamental Online, 2(ed.supl.), 720-724.

Gonzalez, A. C. M., \& Brenes, M. R. (2007). Modificaciones en la sexualidad ocasionadas por el proceso de envejecimiento. In A. C. M. Gonzalez, \& M. R. Brenes (Eds.), Envejece la sexualidade? (pp. 37-75). Buenos Aires: Espacio Editorial.

Gradim, C. V. C, Sousa, A. M. M., \& Lobo, J. M. A. (2007). Prática sexual e o envelhecimento. Cogitare Enfermagem, 12(2), 204-213.

Jodelet, D. (2001). Representações sociais: um domínio em expansão. In D. Jodelet (Ed.), As representações sociais (pp.17-41). Rio de Janeiro, RJ: Ed. UERJ.

Lahlou, S. (2011). Difusão das representações sociais e inteligência coletiva distribuída. In A. M. O. Almeida, M. F. S. Santos, \& Z. A. Trindade (Eds.), Teoria das representações sociais 50 anos (pp. 59-97). Brasília, DF: Technopolitik.

Lima, A. M. M., Silva, H. S., \& Galhardoni, S. (2008). Successful aging: paths for a construct and new 
frontiers. Interface - Comunicação, Saúde, Educação, 12(27), 795-807.

Martins, M. B. (2012). Violência silenciada: violência física e psicológica contra idosas no contexto familiar (Dissertação de Mestrado). Universidade Federal do Amazonas, Manaus, AM.

Maschio, M. B. M., Balbino, A. P., De Souza, P. F. R. \& Kalinke, L. P. (2011). Sexualidade na terceira idade: medidas de prevenção para doenças sexualmente transmissíveis e AIDS. Revista Gaúcha de Enfermagem, 32(3), 583-589.

Masters, W., \& Johnson, V. (1988). O relacionamento amoroso: segredos do amor e da intimidade sexu$a l$. Rio de Janeiro, RJ: Nova Fronteira.

Minayo, M. C. S. (2007). O desafio do conhecimento: pesquisa qualitativa em saúde (5a ed.). São Paulo, SP: Hucitec.

Moscovici, S. (1978). A representação social da psicanálise. Rio de Janeiro, RJ: Zahar.

Moura, I., Leite, M. T., \& Hildebrandt, L. M. (2008). Idosos e sua percepção acerca da sexualidade na velhice. Revista Brasileira de Ciências do Envelhecimento Humano, 5(2), 132-140.

Mucida, A.(2006). O sujeito não envelhece: psicanálise e velhice. Belo Horizonte: Autêntica.

Neri, A. L. (2008). Palauras-chave em gerontologia. Campinas, SP: Alínea.

Neri, A. L.(2002). Teorias psicológicas do envelhecimento. In E. V. Freitas (Ed.), Tratado de geriatria e gerontologia (pp. 32-45). Rio de Janeiro, RJ: Guanabara Koogan.

Pascual, C. P. (2002). A sexualidade do idoso vista com novo olhar. São Paulo, SP: Loyola.

Pires, R. C. C. A. (2006). Sexualidade feminina, envelhecimento e educação: algumas aproximações necessárias. Revista UDESC, 7(1), 1-7.

Ribeiro, A. (2002) Sexualidade na terceira idade. In M. Papaléo Netto (Ed.), Gerontologia: a velhice e o envelhecimento em visão globalizada. São Paulo, SP: Atheneu.

Sá, C. P. (1998). A construção do objeto de pesquisa em representações sociais. Rio de Janeiro, RJ: UERJ.

Santos, A. F. M., \& Assis, M. (2011). Vulnerabilidade das idosas ao HIV/AIDS: despertar das políticas públicas e profissionais de saúde no contexto da atenção integral: revisão de literatura. Revista Brasileira de Geriatria e Gerontologia, 14 (1), 147-157.

Santos, S. S., \& Carlos, S. A. (2003). Sexualidade e amor na velhice. Estudos Interdisciplinares de Envelhecimento, 5(1), 57-80.
Silva, J., \& Saldanha, A. A. W. (2012). Vulnerabilidade e convivência com o HIV/AIDS em pessoas acima de 50 anos. Revista Mal Estar e Subjetividade, 12(3-4), 817-852.

Silva, R. M. O. (2003). A sexualidade no envelhecer: um estudo com idosos em reabilitação. Acta Fisiátrica, 10(3), 107-112.

Silva, R. M. O. (2006). Sexualidade no idoso. In L. H. H Hargreaves (Ed.), Geriatria (pp. 141-148). Brasília, DF: SEEP.

Silva, V. X. L., Marques, A. P. O., \& Fonseca, J. L. C. L. (2009). Considerações sobre a sexualidade dos idosos nos textos gerontológicos. Revista Brasileira de Geriatria e Gerontologia, 12(2), 295-303.

Sousa, J. L. (2008). Sexualidade na terceira idade: uma discussão da Aids, envelhecimento e medicamentos para disfunção erétil. Jornal Brasileiro de Doenças Sexualmente Transmissíveis, 20(1), 59-64.

Soutto Mayor, A., Antunes, E. S. D. C, \& Almeida, T (2009). O "devir" do amor e da sexualidade no processo do envelhecimento. In Anais da VII Jornada Apoiar: Saúde Mental e Enquadres Grupais: a pesquisa e a clínica (pp. 286-293). Laboratório de Saúde Mental e Psicologia Clínica Social Departamento de Psicologia Clínica - IPUSP, São Paulo, SP.

Trindade, Z. A., Santos, M. F. S., \& Almeida, A. M. O. (2011). Ancoragem: notas sobre consensos e dissensos. In A. M. O. Almeida, M. F. S. Santos, \&Z. A. Trindade (Eds.), Teoria das representações sociais 50 anos (pp. 101-121). Brasília, DF: Technopolitik.

Urquiza, A., Thumala, D., Cathalifaud, M. A., Ojeda, A., \& Vogel, N. (2008). Sexualidad em la tercera edad: la imagen de los jóvenes universitários. Ponto $e$ Vírgula,4, 358-374.

Vala, J. \& Monteiro, M. B. (2004). Psicologia social. Lisboa: F.C. Gulbenkian.

Vazquez, L. A., Cabrera, A. R., \& Avich, N. A. (2008). Salud sexual y envejecimiento. Revista Cubana Salud Pública, 34(1). Recuperado de http://scielo.sld.cu/scielo.php?pi$\mathrm{d}=$ S0864-34662008000100010\&script=sci_arttext

Viana, H. B., \& Madruga, V. A. (2010). Sexualidade na velhice e qualidade de vida. Revista Brasileira de Qualidade de Vida, 2(2), 26-35.

Vieira, K. F. L. (2012). Sexualidade e qualidade de vida do Idoso: desafios contemporâneos e repercussões sociais. (Tese de Doutorado), Universidade Federal da Paraíba, João Pessoa, PB. 
Wallace, M. (2003). Sexuality and aging in long-term care. Annals of Long-term Care, 11(2), 53-59.

\section{Kay Francis Leal Vieira}

Doutora em Psicologia Social pela Universidade Federal da Paraíba - UFPB. Docente do Centro Universitário de João Pessoa - UNIPE.

E-mail: kayvieira@yahoo.com.br

\section{Maria da Penha de Lima Coutinho}

Pós-doutora pela Universidade Aberta de Lisboa, Portugal. Docente do Departamento de Psicologia da Universidade Federal da Paraíba.

E-mail: mplcoutinho@yahoo.com.br

\section{Evelyn Rúbia de Albuquerque Saraiva}

Doutora em Psicologia Social pela Universidade Federal da Paraíba - UFPB. Docente Adjunta do Departamento de Psicologia da Universidade Federal da Paraíba.

E-mail: evelynsaraiva@hotmail.com
Endereço para envio de correspondência: Rua Comerciante José Miranda de Araújo, 130 apto. 1001. Jardim Oceania. CEP: 58037-428. João Pessoa - PB. Brasil.

Recebido 09/ 12/2013

Reformulado 15/03/2015

Aprovado 14/09/2015

Received 12/09/2013

Reformulated 03/15/2015

Approved 09/14/2015

Recibido 09/12/2013

Reformulado 15/03/2015

Aceptado 14/09/2015

Como citar: Vieira, K.F.L., Coutinho, M. P. L., \& Saraiva, E. R. A. (2015). A sexualidade na velhice: representações sociais de idosos frequentadores de um grupo de convivência. Psicologia: Ciência e Profissão, 36(1):196-209. doi:101590/1982-3703002392013

How to cite: Vieira, K.F.L., Coutinho, M. P. L., \& Saraiva, E. R. A. (2015). Sexuality in old age: Social representations of elderly patrons of a social group. Psicologia: Ciência e Profissão, 36(1):196-209. doi:101590/1982-3703002392013

Cómo citar: Vieira, K.F.L., Coutinho, M. P. L., \& Saraiva, E. R. A. (2015). Sexualidad en la vejez: representaciones sociales de los frecuentadores de un grupo de convivencia. Psicologia: Ciência e Profissão, 36(1):196-209. doi:101590/1982-3703002392013 